\title{
Research on Application of Virtual Reality Technology in Production Practice of Bioengineering Specialty
}

\author{
Jing Su*, Junqing Wang, Piwu Li, Wenjun Lan \\ School of Bioengineering, \\ Qilu University of Technology (Shandong Academy of Sciences) \\ Jinan, China \\ *sj_12346@163.com
}

\begin{abstract}
Professional production practice is a part of the bioengineering teaching, which plays an important role in improving students' ability to analyze problems and solve problems. However, there are some common problems in the practical teaching of bioengineering specialty. For example, appropriate companies are difficult to find, students have less opportunities to operate and practice funds are inadequate, which seriously affects the practice effect of bioengineering students. In this paper, the virtual simulation technology is introduced into the practice link. By effectively integrating this emerging computer technology with the construction of practice bases and on-campus engineering training, the reform of the bio-engineering practice in production was put forward, the effectiveness of internships was strengthened, and the students' engineering practice ability and comprehensive quality were effectively improved through practice training.
\end{abstract}

Keywords-bioengineering, production practice, virtual reality technology, practice teaching reform

\section{Problems in Traditional Production Practice of BIOENGINEERING SPECIALTY}

Bioengineering is a comprehensive application subject, the purpose of which is to train engineering and technical talents who are engaged in design and production management, new technology research, and new product development in the field of biotechnology and engineering. Therefore, the internship session is a very important part of the professional training for students of bioengineering specialty, which has a direct impact on the quality of talent training in the professional [1-2]. However, there are some problems that need to be solved in the process of production practice.

\section{A. Difficult to find modern management production practice enterprises}

The links of production practice require students to work in the production enterprise and participate in production practice. Therefore, choosing the right practice base is the premise for doing well the production practice. However, at present, most enterprises, especially those with advanced equipment, high degree of automation, more scientific enterprise management and better efficiency, are reluctant to accept college students for production internships. The main reasons are as follows: First, companies in the market economy are pursuing high efficiency and high output. They are reluctant to receive intern students who cannot bring economic benefits and sometimes bring hidden safety risks. Second, due to fierce market competition, companies are unwilling to accept students' internships because of confidentiality principles. Even if a few enterprises receive internship students, students are not exposed to the actual production process during the internship process. Finally, internship is just a superficial visit [3-4].

\section{B. Incomplete internship content}

Most of the bioengineering companies are now large-scale continuous production, requiring continuous and stable production. Therefore, student can only visit the production process rather than getting to work, which is impossible to achieve the purpose of production practice. At the meantime, large-scale production facilities are becoming more systematic and automated, so students cannot master the entire process of the entire project. The lacking of completeness leads to unfamiliarity with production in depth. Moreover, in the production practice, students can hardly combine the theory and practice they have learned. The practice of production has only served to understand the effects of internships. It is difficult to increase the enthusiasm of teachers and students, and the effect of production internships is poor.

\section{Insufficient funding for internship}

The school has a certain amount of investment in internship funding. However, due to the increase in prices, together with the fact that companies tend to charge on receiving production internship as well as additional transportation fees, the funding for the internship is relatively insufficient. All these reasons lead to the shrinkage of production practice, and the time arrangement often reduces from two weeks to one week, which is very difficult to guarantee the quality of internship.

In view of the above problems, on the one hand, the training unit must first attach importance to the construction of an off-campus practice base, extensive cooperation in production, teaching and research, improvement in teaching quality, and establishment of a stable off-campus practice base. On the other hand, modern computer technology should be used to construct a virtual reality internship system to make up for the inadequacies of off-campus practice sessions, break the limitations of traditional internships, open up students' 
horizons, inspire students' interest in learning, and increase the diversity, comprehensiveness, and openness of practical teaching.

\section{Virtual Reality TeChNOLOgy AND Its ApPlicAtion IN BioengineERING PRACTICE}

Virtual reality technology is a technology that uses computers and other devices to simulate the reality with the development of computer technology. It is a science in which computer hardware and software technology, sensor technology, robotics, artificial intelligence, ergonomics, and other disciplines are integrated and interwoven. Using virtual reality technology, people can realistically simulate those phenomena or things in the real world that are high-risk, costly, and irreversible [5-6].

\section{A. Research status of virtual reality technology}

In the past 10 years, the application of process simulation technology in the training of operational skills has gained popularity in many countries around the world. This kind of simulation system can realistically simulate the normal operation of the plant and various accident conditions. It has no danger, can save costs, greatly shortens the training time, and has become a necessary means for many enterprises to assess the operational workers' qualifications for employment. At present, laboratories in many colleges and universities have carried out research work in this area and have obtained a lot of research results. For example, Beijing University of Aeronautics and Astronautics has established the National Key Laboratory of Virtual Reality Technology, and Huazhong University of Science and Technology has established an interactive digital logic virtual experimental teaching platform and other institutions have also conducted extensive research on the realism and three-dimensional reality of virtual reality.

\section{B. Application of virtual reality technology in practical teaching of bioengineering}

The disciplinary characteristics of the bioengineering specialty are based on the primary purpose of providing students with hands-on skills. Using modern industrial production as a means to enable students to systematically master the basic theories, basic knowledge and basic skills of the major and cultivate students' strong sense of dedication and responsibility as well as the ability to analyze and solve practical problems in biological engineering. The application of virtual reality technology in bio-engineering practice teaching can express the teaching content more vividly and concretely, which can improve students' efficiency in mastering knowledge and skills. The industrial production process is a complex system in which a series of unit operating devices are combined by pipelines. These unit operating devices are also monitored and controlled by various regulators, regulating valves, detectors, transmitters, indicators, recorders, or advanced distributed computer control systems, that is, decentralized control loops and centralized data management systems are implemented using computers [7]. The use of computer simulation technology can solve the problem of insufficiencies of practice and poor operability during the internship. Through a set of practical simulation teaching systems that are very similar to the on-site production equipment, the content of practical teaching is displayed vividly and vividly in front of the students. On one hand, students learn about the actual production equipment without leaving the school gate, and can perform repeated operations with their own hands. On the other hand, students can not only have a good understanding of the actual production, but also can use their own hands to improve the professional application skills, and combine the professional knowledge they learn with the actual production, which greatly improves the students' interest and initiative in production practice.

\section{ApPlicAtion of Virtual ReAlity TeChNOLOGy in BIOENGINEERING PRACTICE}

In view of the problems existing in the practice of bioengineering professional production, we explored the application of virtual reality technology in bioengineering practice from several aspects such as the reform of curriculum system, the construction of practice bases, and the training of production, teaching and research personnel. We initially attempted to use virtual reality technology in combination with practice and experiment to construct a virtual training system for the screening of auxotrophs of Escherichia coli by ARTP mutagenesis, a simulation experiment system for prokaryotic gene engineering bacteria, etc.

\section{A. Curriculum system reform}

We should set up a curriculum system which is in line with the training requirements and distinctive features, strengthen the setting of the hands-on links in the course system, strengthen the learning of $\mathrm{CAD}$ drawing and factory design, and cultivate the students' practical skills to improve the ability of connecting the theory with the actual and analyzing the problems and solving the problems. For example, in CAD drawing teaching, the teacher may try to apply the modeling function of the three-dimensional entity to the composite body modeling and display the various combinations of the combination body through the virtual reality software, enabling students to have a certain mastery of the advantages of projected projections and the laws of engineering drawings [8]. In addition, we should adjust the curriculum resources properly, strengthen the construction of virtual simulation curriculum system, increase the computer training time of virtual simulation course, reform the form of curriculum design, change the former form of results submitted only in written form, provide students with the opportunity to build entity model and practical operation, enrich teaching contents with the latest scientific achievements and latest technological achievements, and form a practical teaching system focusing on ability training.

\section{B. Reform of practice base construction}

The training of students' engineering practice ability needs the corresponding engineering practice environment and conditions. Therefore, it is very important for bioengineering students to establish a highly comprehensive production practice base with modern enterprise management and environmental protection. We can lead the students to visit the factory, enabling them to understand the production arrangement and design of the factory, be familiar with the production process of the factory, and deepen the understanding of the production equipment, the regulator and 
the pipe connection in the simulation system. Through the inspection of the control room of the company visited and the control panel of various equipment, students' understanding of modern enterprises' systematization and automation of production management will be further strengthened.

\section{The training mechanism of cooperative talents in production, learning and research}

By employing technical experts as part-time teachers, we carry out extensive cooperation in production, education, and research, such as the "Excellent Engineer Education Training Program" to enrich the teaching content, improve the quality of teaching, and cultivate "double quality" teachers by using the equipment advantages and experience advantages of teaching base enterprises. The young teachers can make use of the opportunity of guiding practice or the spare time of teaching to go deep into the base enterprises, give full play to the characteristics of the market, actively combine the practical teaching with the students, realize the sharing of resources, make the advantages complementary, and strengthen the scientific and technological strength greatly. We can also award grants to enhance enterprise's innovation ability and make enterprises get substantial benefits, so that they will pay more attention to cooperation with universities and attach importance to investment in education.

\section{The EFFECT OF ReForm And Thinking Issues}

At present, our virtual simulation training system is still being built and improved step by step. In the course of professional teaching, we gradually increase the teaching cases, for example, through chemical simulation; the students have a preliminary understanding of modern large-scale industrial production. Through computer simulation operation, students have certain practical operation skills, and their understanding of production equipment has deepened on visiting the factory. In order to effectively provide students with hands-on opportunities, combined with the current characteristics of bio-engineering and development direction, we have established the first micro-brew production line in China. The production line is designed and manufactured by ourselves and integrated with teaching, scientific research and production. At present, the equipment is updated to feed $1000 \mathrm{~L}$ at a time, ferment 5000L and produce 300L beer daily. The production process is completely the same as the industrial production process, which enables students to carry out practical operation and system analysis from the aspects of raw material preprocessing, culture medium preparation, bacterial culture, fermentation tank sterilization, inoculation and fermentation process parameters control, product separation and extraction, etc., really combine theory with practice skills, and achieve the purpose of production practice.

\section{CONCLUSION}

In summary, in response to the problems existing in the production practice of traditional biological engineering, the author proposes to apply virtual reality technology in production practice. This is an attempt and exploration of the reform of bio-engineering production practice. It solves some of the difficulties encountered in the internship process, increases the diversity of practical teaching, stimulates enthusiasm of the students and has achieved good teaching results.

\section{REFERENCES}

[1] Zhang Huiling, Fang Haitian. Reform and Discussion of the Combination of Teaching and Practice - Fermentation Engineering Teaching and Practice. Research in University Laboratory Work, 2007, 91(1): 8-10.

[2] Zhao Likun. Exploration and Practice of Improving Teaching Quality of Fermentation Engineering. Guangxi Journal of Light Industry, 2009, 127(6): 160-161.

[3] Hu Yufang. Discussion on Improving the Quality of Production Practice [J] . Research and Exploration in Laboratory, 2005, 24(9):406-407.

[4] Wang Jihui. Reform and Practice of Undergraduate Production Practice [J] . Research and Exploration in Laboratory, 2005, 22(9):15-17.

[5] Shen Wei, Zeng Wenqi. Virtual Reality Technology [M]. Beijing: Tsinghua University Press, 2009.

[6] Xu Wei. Research Status and Development of Virtual Reality Technology at Home and Abroad [J ]. Modern Business Trade Industry, 2009( 2) : 279 - 280

[7] Yang Xuefu, Deng Yu, Bao Yuxiang. Thinking on Practice Teaching System in Teaching Local Universities. Journal of Jiujiang University, 2006, 15(2): 107-112.

[8] Sheng Xia, Pan Qian. Application of Virtual Display Technology in Modern Display Design Teaching. Journal of Suzhou University, 2015(3):124-127 